\title{
Iranian EMS System
}

\section{Masoud Saghafinia, MD; Mohammad Hosein Kalantar Motamedi, DDS}

Trauma Research Center, Department of Anesthesia, Baqiyatallah Medical Sciences University, Tehran, Islamic Republic of Iran

Online publication: June 30, 2014

doi:10.1017/S1049023X14000569
We read with interest the article "Emergency Nursing Staff Dispatch: Sensitivity and Specificity in Detecting Prehospital Need for Physician Intervention During Ambulance Transport in Rovigo Emergency Ambulance Service, Italy" by Leopardi and Sommacampagna. ${ }^{1}$ Regarding the Iranian EMS system; several points merit mention:

1. Physician based EMS systems are common in Europe ${ }^{2}$ but in Iran it is paramedicbased.

2. Physician-based EMS has several advantages:

a. Physicians are trained in diagnosis and treatment of complicated emergencies and can provide diagnosis and treatment at the scene; this can be life-saving ${ }^{3}$

b. The presence of a physician at the scene of the accident may give the families more trust and assurance

c. Physicians can make timely decisions for complicated patient management

d. Physicians can manage complicated CPR, intubation and patient transport to the hospital.

e. Physicians are better able to relay the diagnosis to the hospital staff where the patient is transported.

Physician-based EMS has several disadvantages:

a. In many instances, the physicians are not required at the scene of the accident and the actions can be performed by a qualified nurse

b. There are not enough physicians in Iran and traffic accidents are at an all-time high

c. Physician salary is insufficient.

In any case, in Iran, EMS training must be repeated once every two years for nurses and doctors; assessment and resuscitation training has to be repeated and evaluated. ${ }^{4}$

References

1. Leopardi M, Sommacampagna M. Emergency nursing staff dispatch: sensitivity and specificity in detecting prehospital need for physician interventions during ambulance transport in Rovigo Emergency Ambulance Service, Italy. Prehosp Disaster Med. 2013;28(5):523-528.

2. Miller RD, Eriksson LI, Fleisher L, Wiener-Kronish JP, Young WL. Miller's Anesthesia, 7th ed. London: Churchill Livingstone; 2010.

3. Ravari H, Abrishami M, Ghezel-Sofla M, Vahedian-Shahroodi M, Abrishami M. Knowledge of medical interns regarding cardio- pulmonary resuscitation. Trauma Mon. 2012;17(1):242-244.

4. Mokhtari Nori J, Saghafinia M, Kalantar Motamedi MH, Khademol Hosseini SM. CPR training for nurses: how often is it necessary? Iran Red Crescent Med J. 2012;14(2):104-107. 